\title{
Organo-Bentonit Üretimi ve Organo-Bentonitlerin Kirlilik Giderimi Çalıșmalarında Kullanımı
}

\author{
Esra ORUÇOĞLU ${ }^{1}$, Sevilay HACIYAKUPOĞLU² \\ ${ }^{1}$ Istanbul Teknik Üniversitesi, Maden Fakültesi, Ayazağa Kampüsü, 34469, İstanbul

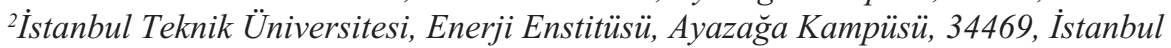

\begin{abstract}
ÖZET
Son yıllarda organo-bentonitlerin birçok alanda kullanımının arttığı görülmektedir. Organo-bentonitler, bentonitlerden katı hal tepkimesi veya iyon değişimi yöntemleriyle sentezlenirler. Ancak, çoğunlukla iyon değişimi yöntemi uygulanır ve çeşitli organik bileşik katyonlarının, bentonit yapısındaki katyonlarla yer değiştirmesiyle elde edilirler. Organik bileşik katyonunun yapısı ve üretim koşulları elde edilen organo-bentonitin özelliklerini etkilemektedir. Örneğin bentonit yapısında, uzun zincirli alkil amonyum katyonlarının kullanıldığı durumlarda, üretim koşullarına bağlı olarak bentonitte tabakalar arası boşluk mesafesinin fazlasılyla artması, üretilen malzemelerin yüzey özelliklerinin hidrofilden hidrofoba dönüşmesi, yüzey enerjisinin düşmesi veya yüzey yükünün negatiften pozitife dönüşmesi gibi, değişiklikler olabilmektedir. Organo-bentonitler kullanılarak kirlilik önleme ve çevresel iyileştirme, reolojik katk1 malzemesi üretimini içeren endüstriyel uygulamalar, polimerik nanokompozit üretimini kapsayan malzeme bilimi araştırmaları gibi farklı alanlarda uygulanabilen çok sayıda araştırma yapılmıştır. Çevresel kirliliklerin gideriminde ve önlenmesinde organo-bentonitlerin kullanımı konularında yapılan araştırmalarda, endüstriyel atıklardaki kirliliklerin farklı özellikte olabileceği ve kirlilik gideriminde kullanılacak malzemenin bu kirliliklerin birçoğunu tutabilecek özelliklere sahip olması düşüncesinden yola çıkılarak, organo-bentonit üretilebilirliği ve üretilen organo-bentonitlerde anyonik, katyonik veya organik kirleticilerin soğurulması, ayrı ayrı veya birarada incelenmiştir. Bu derleme çalışmanın amacı, bentonitleri organik bileşiklerle modifiye ederek organo-bentonitlerin üretilmesi ve bu modifiye malzemelerin kirlilik gideriminde kullanımı çalışmalarıyla ilgili konularda bugüne dek yapılıış araştırmalarla ilgili önemli gelişmeleri değerlendirip, genel bir bakış sunarak literatüre katkıda bulunmaktır.
\end{abstract}

Anahtar kelimeler: Organo-bentonit, kuvaterner alkil amonyum, adsorpsiyon, soğurulma, kirlilik giderimi

\section{Production of Organo-Bentonites and Their Usage in Pollution Removal Studies}

\begin{abstract}
Nowadays, organo-bentonite usage has been growing in many areas. Organo-bentonites are synthesized from bentonites by using solid state reactions or ion-exchange methods. Generally ion-exchange is applied and various organic cations are used. They are displaced with exchangeable cations found in bentonite structure. Organic cation properties and production conditions influence product properties. For instance, when the long chain alkyl ammonium cations are used, depending on the synthesis conditions basal space can be increased greatly, surface properties can change to hydrophobic, surface energy can decrease or surface charge can transform to positive. Many researches are made by using organo-bentonites in different fields such as pollution prevention, environmental improvement, rheological additive production for industrial applications and polymeric nanocomposite production for material science applications. In pollution related researches, the properties of the pollutants in wastes can be different and sorbent structure used should sorb many of these pollutants. Based on this idea, organo-bentonite producability under different experimental conditions is investigated and sorption/adsoption mechanisms of anionic, cationic, or organic pollutants onto these organo-bentonites are determined. Purpose of this study is to contribute literature by providing an overview including important developments about production and sorption studies of organo-bentonites with the help of researches executed so far.
\end{abstract}

Keywords: Organo-bentonite, quaternary alkylammonium, adsorption, sorption, pollution removal.

\section{GiRis}

Çevresel kirliliklerin uzaklaştırılmasında, kirleticiler ile kirlilik gideriminde kullanılan malzemeler arasında gerçekleşen etkileşimlerden yararlanılan çeşitli fiziksel ve kimyasal yöntemler uygulanmaktadır [1-3]. Bu etkileşimlerden biri olan adsorpsiyon gaz-katı, gaz-sıvı, sıvı-katı veya sıv1-sıvı ara yüzey tabakasında bir bileşenin derişiminin ortam fazındaki derişiminden daha yüksek veya daha düşük olması durumu olarak tanımlanmıştır [4]. Benzer anlamda kullanılan soğurulma ise adsorpsiyon, absorpsiyon,

Sorumlu yazar/Corresponding author: Esra ORUÇOĞLU. Tel: +90 (212) 28561 83, e-posta: orucoglu@itu.edu.tr Gönderilme/ Submitted: 11.07.2014, Kabul/Accepted: 01.07.2015 
yüzeyde çökelme ve yüzeyde film tabakası oluşumu kavramlarını içermektedir [5]. İncelenen çalışmaların bir kısmında organo-bentonitlerin adsorban olarak kullanımı, bir kısmında ise soğurucu malzeme olarak kullanımı araştırıldığından, bu çalışmada da, incelenen makalelerdeki terimlerin kullanılmasına özen gösterilmiştir.

Üstün fiziksel ve kimyasal özelliklerinde dolayı bentonitler çevresel kirliliklerin gideriminde ve önlenmesinde kullanılmaktadırlar [2, 6-8]. Ancak özellikle hidrofilik özelliği ve negatif yüzey yükü nedeniyle katyonik kirliliklerin gideriminde etkin olan bentonitler, anyonik ve hidrofobik kirliliklerin gideriminde etkin olamamaktadırlar. $\mathrm{Bu}$ amaçla killerin modifiye edilerek kullanılabilmesi konularında araştırmalar yapılmaktadır [9-12].

Günlük hayatı etkileyen birçok alanda organo-bentonitlerin kullanımı her geçen gün daha da yaygınlaşmaktadır. Birçok farklı tür kil mineralinden organik bileşikler kullanılarak organokiller üretilir. Simektit grubu killer içinde yer alan ve büyük bir çoğunluğunu montmorillonit mineralinin oluşturduğu bir kil çeşidi olan bentonit, organik bileşikler eklenmesiyle elde edilen kompozitler organo-bentonit olarak adlandırılır [13-16]. Organokil üretiminde tüm killer içinde en çok kullanılan kil türleri, yüksek adsorpsiyon kapasiteleri nedeniyle smektitler ve özellikle montmorillonitlerdir [17]. Kil mineralleri farklı organik bileşiklerle farklı şekillerde trpkimeye girebilirler. Kaolin türü killer belirli organik bileşikleri tabakaları arasına adsorplarken, simektit ve vermikülit gibi 2:1 tabakalı kil minerallerinin davranışı ara tabaka boşluklarındaki su moleküllerinin birçok polar organik molekül ile yer değiştirmesi veya aratabaka katyonları ile doğal organik ligandların kompleks oluşturması ya da ara tabaka katyonlarının çeşitli organik katyonlarla yer değiştirmesi gibi çeşitli tepkimelerle gerçekleşir [17-18]. Montmorillonit, vermikülit gibi 2:1 tabakalı yapıya sahip kil minerallerinin aratabaka mesafesi arttırılmaya daha elverişli olduğundan, organo-bentonit olarak isimlendirilen organokillerin üretiminde genellikle bu tür kil minerallerinden yararlanılmaktadır. Üretim ve karakterizasyon yöntemleri kullanılan kil türüne göre değişiklik göstermemektedir [13, 16, 19].

Organo-bentonit üretimi süreci 1940 'lı yılların sonlarına doğru araştırmacıların yüksek iyon değiştirme kapasitesine sahip ve tabakalı killerden olan bentonite bazı organik grupları ekleyerek, killerin yüzey özelliklerindeki değişimi incelemeleri ile başlamıştır. Organo-bentonit üretimini etkileyen faktörlerin incelenmesi, ürünlerin karakterizasyonu, çeşitli organik, anyonik ve katyonik kirliliklerin adsorpsiyonunda ve nanokompozit üretiminde kullanımı konularındaki araştırmalar ile günümüze kadar devam etmiştir [20-33]. Jordan (1949) çalışmasında başlangıçta oldukça hidrolfilik yapıda olan killerin hidrofobik ve organofilik özelliklere dönüşüm oranını ve bu dönüşümü etkileyen faktörleri incelemiştir. Çalışma sonuçları, uygun organik madde seçildiğinde kilin yapısında organofilik yapıya dönüşmesi bakımından şaşırtıcı bir değişimin olduğunu göstermiştir [20]. Jordan ve diğ. (1950) yaptıkları diğer bir çalışmada iyon değiştirme yöntemiyle çeşitli alifatik amonyum bentonit kompleksleri hazırlamışlardır ve bu malzemelferin birçok organik sıvıda ve organik sıvı karışımlarındaki jelleşme özelliklerini incelemişlerdir. Kil ve organik amonyum tuzları arasında tam iyon değiştirme gerçekleştiğinde optimum jelleşmenin olduğunu göstermişlerdir [21]. Slabaugh ve Culbertson (1951) çalışmalarında bentonit sistemindeki hidrojen iyonları ile organik aminler arasındaki kimyasal tepkimeyi viskometrik analizle inceleyerek organo-bentonit komplekslerinin oluşum mekanizmalarını açıklamışlardır [22]. Greenland ve Quirk (1960) çalışmalarında modifikasyonla killerin fiziksel özelliklerinde meydan gelen değişimin kontrol edilmesinin önemli olduğunu ve bunun için gerçekleşen adsorpsiyon mekanizmasının anlaşılması gerektiğini belirtmişlerdir. Bu kapsamda 1-n-alkil piridinyum bromürlerin $\mathrm{Na}$ - ve $\mathrm{Ca}-$ montmorillonite adsorpsiyonunu inceleyerek adsorpsiyon izotermlerini oluşturmuş ve XRD ölçümleriyle bazal boşluk mesafelerini belirlemişlerdir [23]. Slabaugh (1971) çeşitli sicaklık artırımlarıyla 400 C'ye kadar artırılan sicaklıkta kısmen bozunan organo-bentonitlerin hidrofilik/hidrofobik özelliklerini incelemiş̧tir [25]. Zhang ve diğ. (1993) üç farkli kuvaterner amin katyonlarının Na- ve K-bentonite adsorpsiyonunu ve desorpsiyonunu incelemişlerdir. Katyon değiştirme kapasitesinin \% 70'inden daha az katyon eklendiğinde her üç katyonun da \% 99'undan fazlasının montmorillonitlere soğurulduğu gözlenmiştir. Kuvaterner amin katyonlarının soğurulmasının, en az iki mekanizma (katyon değiştirme tepkimesi ve aminlerin iyon değişimi olmayan yüzeylere adsorpsiyonu) ile gerçekleştiği belirtilmiştir. Ayrıca adsorplanan kuvaterner aminlerin fazla miktarda $\mathrm{NaCl}$ veya $\mathrm{KCl}$ bulunan ortamlarda bile kolaylıkla desorplanmadığı gözlenmiştir [28]. Mortland ve diğ. (1986) çalışmalarında farklı kuvaterner amonyum katyonlarının katyon değiştirme yöntemi ile simektit mineraline eklenmesiyle çeşitli kil-organik kompleksleri sentezlemiş ve bu bileşikleri fenol ve klorofenollerin adsorpsiyonunda kullanmışlardır. Çalışmada adsorplanan fenol bileşiklerinin miktarının, adsorplayan madde-adsorplanan madde ve adsorplanan madde-ç̧̋zücü etkileşimine bağlı olarak değiştiği gözlenmiştir [27]. Choy ve diğg. (1997) farklı kuvaterner amonyum katyonları kullanarak organobentonitler üretmişlerdir. XRD, FTIR analizleri ve viskozite 
ölçümleriyle bentonitin aratabakasında meydana gelen yapısal değişimleri araştırmışlardır [29]. Moraru (2001) çalışmasında adsorpsiyon, XRD, reolojik, elektrokinetik, dielektrik ve kalorimetrik ölçümleri kullanarak, farklı polariteye sahip olan organik sıvilardaki alkilamonyummontmorilonit türevlerinin jel oluşumu mekanizmasını araştırmıştır ve modifikasyonun, organik katyon türünün, alkil zincir uzunluğunun, organik çözelti ve polar katk1 maddesinin türünün etkileri, jel oluşumu ve organojellerin çeşitli özellikleri incelenmiştir [30]. Senturk ve diğ. (2009) katyonik yüzey aktif madde ile modifiye ettikleri organo-bentonitleri kullanarak sıvı çözeltilerden fenol giderimini incelemişlerdir. XRD, FTIR ve SEM yöntemleri ile ürettikleri malzemenin karakterizasyonunu yapan araştırmacılar $\mathrm{pH}$, temas süresi, başlangıç fenol derişimi, organo-bentonit derişimi, sıcaklık gibi çeşitli deneysel paramentrelerin fenol adsorpsiyonuna etkisini de araştırmışlardır [31]. Su ve diğ. (2011) çalışmalarında çeşitli katyonik yüzey aktif maddelerle modifiye ettikleri organobentonitleri arsenik gideriminde kullanmışlardır. XRD, FTIR ve SEM yöntemleri ile üretilen bentonitler karakterize edilmiştir. Bir diğer çalışmada, organik modifikasyonun, bentonitin arsenik adsorpsiyonunu artırdığı gözlenmiştir ve adsorpsiyona arsenik türünün, $\mathrm{pH}$ 'ın, iyonik kuvvetin ve diğer anyonların etkisi araştırılmıştır. As(III) ve As(V) adsorpsiyonunun çözelti pH'ına çok bağlı olduğu, iyonik kuvvetteki artışın ve diğer anyonların eklenmesi As(V) adsorpsiyonunu azaltırken As(III) adsorpsiyonunu pek etkilemediği sonucu elde edilmiştir [32].

Organo-bentonitler soğurucu malzeme olarak atık suların arıtımında, toprakta, suda ve havada kirliliklerin yayılmasını azaltmada [34-38], yağ, zirai ilaç, deterjan, nitrobenzen, anilin, naftol ve fenol gibi iyonik olmayan organik kirliliklerin ve pestisitler gibi zehirli bileşiklerin gideriminde $[2,13,17$, 36, 37, 39-44], anyonik ve katyonik kirliliği önlemek için bariyer malzemesi olarak tehlikeli atıkların düzenli depolama alanlarında, radyoaktif atık gömülerinde ve diğer jeoteknik bariyer uygulamalarında [36, 39,45-50], güçlendirici dolgu malzemesi olarak plastiklerde ve elektrik endüstrisinde [51], kıvamlaştırıcı malzeme olarak boyalarda, yapıştırıcılarda, sondaj çamurunda, kozmetikte ve makina yağlarında [30, 52, 53], dolgu malzemesi olarak organik-inorganik hibrit, kompozit ve nano ölçekli kompozit uygulamalarında [5456], bentonit minerallerinin polimerik matris içinde homojen dağılımını sağlamada, mekanik, fiziksel ve kimyasal özelliklerini geliştirmede ve bazen de maliyeti düşürmek için polar polimerler ile nanokompozit yapımında kullanıldığ 1 birçok çalışma yapılmıştır [52, 57-59].

Hazırlanan bu derleme çalışmasında amaçlanan, bentonitlerden çeşitli organik bileşiklerle modifikasyonla organo-bentonitlerin üretilmesi ve bu modifiye malzemelerin kirlilik gideriminde adsorban veya soğurucu malzeme olarak kullanımı ile ilgili konularda bugüne dek yapılmış araştırmalardan elde edilen önemli gelişmeleri değerlendirip, genel bir bakış sunarak literatüre katkıda bulunmaktır.

\section{ORGANO-BENTONITLER}

Organo-bentonitler doğal bentonitlere göre daha organofilik yapıdadırlar ve polar olmayan organik çözeltileri soğurma kapasiteleri daha fazladır. Bentonit modifikasyonunda yaygın şekilde yüzey aktif madde (YAM) olarak alkil amonyum iyonları, endüstriyel uygulamalarda da özellikle kuvaternar alkil amonyum iyonları kullanılır; modifikasyonda kullanılan diğer önemli organik bileşik grupları ise katyonik boyalar ve katyonik komplekslerdir[18]. Bentonitte tabakalar arası boşluk mesafesi üretim koşullarına bağlı olarak çok artabilir, üretilen malzemelerin yüzey özellikleri hidrofilden hidrofoba dönüşebilir, yüzey enerjisi düşebilir ya da yüzey yükü negatiften pozitife dönüşebilir [37, 39, 41, 60].

\subsection{Organo-bentonitlerin Üretilmesi}

Organo-bentonitler bentonitler ile katı hal tepkimesi veya çözeltilerde katyon değiştirme işlemi gibi farklı yöntemler kullanılarak üretilmektedirler. Katı hal tepkimesi yönteminde, organik moleküllerin herhangi bir çözücü madde kullanılmadan, kuru kil minerallerinin diş yüzeyine tutunarak kompleks oluşturmalarıyla modifiye bentonit üretilir. Silikat tabakaları arasına katyon geçişi olmaz, bu yöntem yaygın olarak kullanılan bir yöntem değildir. Katyon değiştirme yönteminde ise, bentonit içinde bulunan ve yer değiştirebilen katyonların, iyon değişimi yöntemi ile genellikle sulu çözeltideki kuvaterner alkil amonyum ya da farklı organik bileşik katyonları ile yer değiştirmesi ile modifiye bentonit üretilir [18, 40, 52, 53, 57]. Organobentonit üretiminde çoğunlukla kullanılan alkil amonyum türleri alkil, fenil, benzil, piridil gruplarını içeren kuvaterner amonyum bileşikleridir. Bazı durumlarda alkil ve alkenil amonyum iyonları da kullanılır; fakat genellikle kuvaterner alkil amonyum katyonları kullanılmaktadır [36, 39]. Diğer kil türleri kullanılarak organokil üretilmesinde de aynı yöntemlerden yararlanılır [14, 15, 17].

Hidrofilik baş kısımlı ve uzun hidrofobik zincirli moleküllerden oluşan kuvaterner alkil amonyum türevi bileşikler bulundukları çözeltilerin yüzey gerilimini de değiştirirler [18]. Şekil 1'de YAM olarak kullanılan 1-heksadesil piridinyum klorür (HDPy-Cl), heksadesil trimetil amonyum klorür (HDTMA-Cl), benzetonyum klorür (BE-Cl), 1,12-dipiridinyum dodekan dibromür (DPyDD$\left.\mathrm{Br}_{2}\right)$ organik bileşiklerinin yapıları görülmektedir $[46,61]$. 


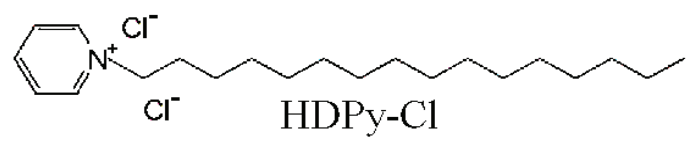<smiles>CC(C)(C)CC(C)(C)c1ccc(OCCOCC[N+](C)(C)Cc2ccccc2)cc1</smiles>
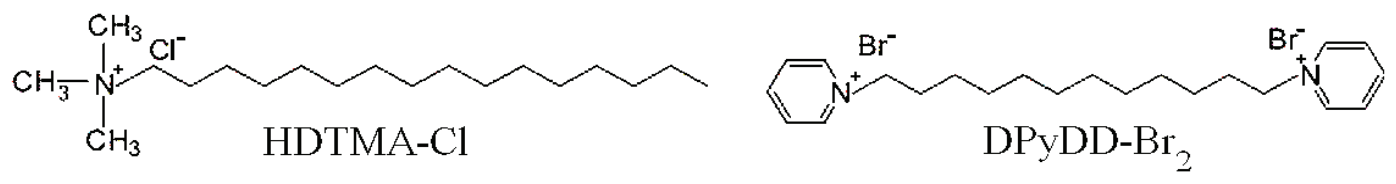

Şekil 1. Bazı organik YAM bileşikleri ([46]'dan uyarlanmıştır)

Üretilmesi istenen organo-bentonitte oluşturulması istenen tabaka yapısına göre (tek tabakalı, iki tabakalı veya parafin tipi) eklenecek organik katyon miktarı $\mathrm{m}_{\text {katyon }}$, kullanılan bentonitin katyon değiştirme kapasitesi de göz önüne alınarak, aşağıdaki denklem ile hesaplanır [39, 62]:

$\mathrm{m}_{\text {katyon }}=\mathrm{f} \cdot \mathrm{KDK} \cdot \mathrm{m}_{\text {bentonit }} \cdot \mathrm{M}_{\text {katyon }} \cdot \mathrm{Z}$

Bu denklemde KDK (eşdeğer kütle/kütle) bentonitin katyon değiştirme kapasitesini, f boyutsuz sayısı eklenecek organik katyon miktarının belirleneceği katyon değiştirme kapasitesi kesrini (örneğin \% $200 \mathrm{KDK}$ için $\mathrm{f}=2$ ), $\mathrm{m}_{\text {katyon }}$ (kütle) istenen katyon değiştirme kapasitesi kesrini sağlamak için gerekli organik katyon miktarını, $\mathrm{m}_{\text {bentonit }}$ bentonit miktarını (kütle), $\mathrm{M}_{\text {katyon }}$ (kütle/mol) organik katyonun moleküler kütlesini, $\mathrm{Z}$ (mol/eşdeğer yük) kullanılan organik katyonun eşdeğer yüküne göre mol sayısını (örneğin +2 değerlikli katyon için $Z=1 / 2$ ) ifade etmektedir.

Organo-bentonit üretilmesi için öncelikle modifiye edilmek istenen bentonit saf suya yavaş yavaş eklenir ve tamamen açılana kadar karıştırıcıda karıştırılır. Organo-bentonitlerinin üretilmesinde genellikle ağırlıkça \% 5 'den düşük oranlarda bentonit-su karışımı kullanılmaktadır; fakat daha yüksek oranlarda bentonit-su karışımının kullanılıp, karıştırma sonrası ortama su eklendiği çalışmalar da vardır [32,55, 63 , 64]. Daha sonra bentonit-su karışımına karıştırma sürerken, belirlenen derişimde hazırlanan organik YAM çözeltisi, belirlenen damlatma hızıyla eklenir. Kullanılan organik bileşiğin çözünürlüğünün düşük olduğu durumlarda, çözücü olarak genellikle su-alkol karışımından yararlanılmaktadır $[14,18,29,59,65,66]$. Eklenecek organik madde miktarı kullanılan bentonitin katyon değiştirme kapasitesine eşdeğer veya katları olacak şekilde belirlenir [39, 41]. Karıştırma işlemine organik madde eklenmesi bittikten sonra da belli bir süre devam edilir. Araştırmacılar üretim sırasında farklı karıştırma süreleri uygulamaktadırlar; örneğin bir çalışmada organik madde eklenmesinin ardından oda sıcaklığında 2 saat karıştırma uygulanırken, bir diğerinde 24 saat karıştırılmıştır [37, 67]. Krishna ve diğerleri (2000) ise çalışmalarında YAM ile bentonit arasındaki denge oluşumunu anlamak için, 30 dakika ile 7 gün arasında değişen farklı sürelerde karıştırma süreleri uygulayarak deneyler yapmışlardır [34].

Katyon değiştirme yöntemini kullanan bazı araştırmacılar doğal şartlarda [34, 37], bazıları da sıcaklık kullanarak organo-bentonit üretmişlerdir. Bu çalışmalarda sıcaklık uygulanmas1, organik YAM'nin bentonit süspansiyonuna eklenmesi sırasında gerçekleştirilmiştir $[35,55,63,68$, 69]. Organik madde eklenirken ve daha sonra devam eden karıştırma esnasında $50-60{ }^{\circ} \mathrm{C}$ civarındaki sıcaklık tepkimesi hızlandırdığı için, işlem süresini kısaltmaktadır [29, 59, 63, 65]; üretim sırasında $80{ }^{\circ} \mathrm{C}$ gibi daha yüksek sicaklıkların kullanıldığ

Malzeme yüzeyinde kalarak safsılılı oluşturabilecek organik bileşik fazlası ve YAM'den gelen $\mathrm{Cl}^{-}, \mathrm{Br}^{-}$gibi anyonların üretilen malzemeden uzaklaştırılması için, ürün distile su ile defalarca yıkanarak vakumda süzülür. $\mathrm{Cl}^{-}, \mathrm{Br}^{-}$ gibi anyonların malzeme yüzeyinde kalıp kalmadığ $\mathrm{AgNO}_{3}$ çözeltisi kullanılarak veya yıkama suyunun iletkenliği ölçülerek tespit edilir. Oluşan organo-bentonitler daha sonra santrifüjlenerek çözeltiden ayrıştırılır, oda şartlarında, etüv $[39,67,70]$ veya mikrodalga firın $[55,70]$ kullanılarak veya dondurularak $[60,71]$ kurutulur, ögütülür ve böylece kullanıma hazır hale getirilir [55, 57, 72].

Organo-bentonit üretiminde kullanılan YAM'ler sulu çözeltilerde düşük derişimlerde moleküler olarak dağılırlar; belirli bir derişime ulaştıklarında ise kendi kendilerine topaklanarak miselleri oluştururlar, bu derişim kritik misel derişimi (KMK) olarak adlandırılır [73]. YAM derişimi KMK'ndan daha küçük olduğunda, YAM molekülleri anyon ve katyonlara dönüşerek tamamen iyonize olurlar ve bu iyonlar bentonitin ara tabaka galerilerindeki değişebilen katyonlarla yer değiştirirler; bu aşamada Van der Waals 
kuvvetleri yeterince etkin değildirler. KMK'ndan daha büyük derişimlerde ise oluşan miseller ve katyonlar bentonitin ara tabakalarında adsorplanabilirler. Fakat miseller güçlü bir şekilde montmorillonit yüzeyine tutunmadığından, ara tabakada tutundukları yerden ayrilabilirler [66].

Bentonite KDK değerinden düşük miktarda YAM yüklenmesinde, YAM'nin monomerleri iyon değişimi yöntemi ile kile tutunarak tek tabakalı bir yapı oluştururlar. Bentonitin KDK değerinin üzerinde YAM kullanıldığında iyon değişimi ve elektrostatik etkileşim mekanizmaları organo-bentonitlerin oluşumunda etkin olmaktadır. KDK değerinin üzerindeki YAM yüklenmesi ise, polar olmayan hidrokarbon zincirleri arasında oluşan Van der Waals etkileşimi nedeniyle iki tabakalı yapı oluşmasını sağlar. Kullanılan YAM miktarının daha da arttırılmasıyla parafin tipi yapı oluşur; buradaki hidrofobik etkileşim nedeniyle ara tabakalara giren YAM'leri de birbirinden ayırmak zordur $[17,37]$.

Şekil 2'de alkil amonyum iyonlarının simektit tipi killerin aratabaka boşluklarındaki yerleşimlerinde görüldüğü gibi, ardısıra iki silikat tabakasının başlangıçları arasındaki mesafe olan bazal boşluk genişliği, eklenen organik YAM miktarı ile orantılı olarak artar. Bu genişlik bentonitlerde yaklaşık 1,1 nm civarındadır; tek tabakalı organobentonitlerde 1,3-1,4 nm, iki tabakalı organo-bentonitlerde 1,8-1,9 nm arasında ve parafin tipi organo-bentonitlerde de 2,2 nm üzerinde bir değer almaktadır [18].

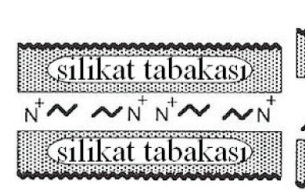

a)

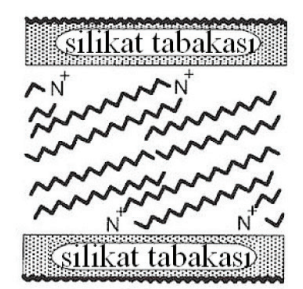

d)

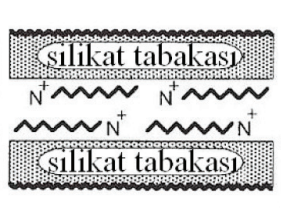

b)

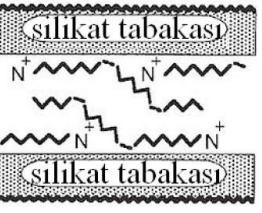

c)

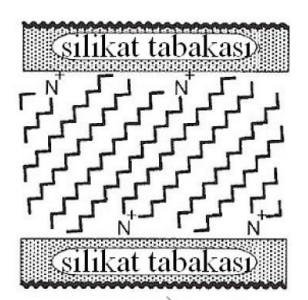

e)
Şekil 2. Alkil amonyum iyonlarının simektit tipi killerin aratabaka boşluklarındaki yerleşimleri: a) tek tabakalı yapı b) iki tabakalı yapı c) pseudo üç tabakalı yapı d, e) parafin tipi yapılar ( [18]'den uyarlanmıştır)
Bentonitlerin organik malzemeyle modifikasyonu sonrası oluşan yapıların anlaşılması için X-ışını Kırınımı Analizi (XRD), Fourier Dönüşümlü Kızıl Ötesi

Spektroskopisi (FTIR), Termal Gravimetrik Analiz/ Diferansiyel Termal Analiz (TGA/DTA) yaygın olarak kullanilırken [9, 17, 37, 61, 68, 74-76], Brunauer Emmett Teller yöntemiyle yüzey alanı ölçümü (BET) [9, 34, 36, 37], Taramalı Elektron Mikroskopisi (SEM) [69], Transmisyon Elektron Mikroskopisi (TEM) [41, 73], zeta potansiyeli [36], Ultraviyole ve Görünür Işık Spektroskopisi (UV-Vis) [77], Nükleer Manyetik Rezonas Spektroskopisi (NMR) [17], toplam organik karbon miktarı (TOC) [9, 12],yöntemleri de zaman zaman bu yöntemlere ek olarak kullanılan başlıca yöntemler arasındadır. Organo-bentonitlerin karakterizasyonunda kullanılan yöntemler, aynı zamanda farklı killer kullanılarak elde edilen organokillerin karakterizasyonunda da kullanılırlar [14, 16, 19].

\subsection{Organo-Bentonitlerin Kirlilik Gideriminde Adsorban veya Soğurucu Malzeme Olarak Kullanımı}

Organo-bentonitlerin çeşitli amaçlarla kullanıldığı adsorpsiyon çalışmaları incelendiğinde, anyonik, katyonik, organik gibi çeşitli kirliliklerin giderilmesi konularında araştırmalar yapıldığı belirlenmiştir. Özellikle, endüstriyel çalışmalarda ortaya çıkan atıklar içerisinde farklı özellikte kirlilikler olabilmektedir ve kirlilik gideriminde kullanılacak malzemenin bu kirliliklerin birçoğunu tutabilecek kapasiteye sahip olması istenmektedir. $\mathrm{Bu}$ nedenle araştırmacılar kirleticilerin özelliklerini dikkate alarak organo-bentonitler üretmişler ve üretilen organobentonitlerde anyonik, katyonik, organik gibi çeşitli farklı yapılara sahip kirleticilerin adsorpsiyonunu, ayrı ayrı veya birarada incelemişlerdir.

\subsubsection{Anyonik kirliliklerin giderimi}

Riebe ve diğerleri (2005) tarafindan bentonit ve vermikülit killerinden dört farklı organik katyon ile farklı organobentonitler üretilmiştir ve organofilik killerin adsorpsiyon öncesinde ve adsorpsiyon sirasında farklı sıcaklıklara maruz kaldığı durumlar için farklı konsantrasyonlardaki radyoaktif iyot adsorpsiyonları incelenmiştir. Denenen tüm organo-bentonit sistemleri oda sıcaklığında yüksek iyot adsorplarken, artan sicaklıkla iyot adsorpsiyonu bir dereceye kadar azalmaktadır; adsorpsiyon azalması sıcaklığın adsorpsiyon işlemi sırasında artması durumunda daha da belirgin olmaktadır. Radyoaktif atıkların ileri soğuma aşaması sırasında gömü sistemindeki atık bariyerlerinin 
korozyonu beklendiğinden, kil bariyerinin beklenen radyonüklid sızıntısından önce yüksek 1sılara maruz kalacağı düşünülmektedir. Bu çalışma, adsorpsiyon öncesi maruz kalınan yüksek sıcaklığın adsorpsiyona etkisinin az olduğunu göstermiştir. Deneylerde 1sıtma sırasında bazal boşluktaki değişime bakılmış ve sonuçlar organobentonit minerallerinin $180^{\circ} \mathrm{C}$ 'ye kadar dayanıklı olduğunu göstermiştir. 12 farklı organo-bentonit kombinasyonundan altı tanesi anyon adsorpsiyonu ve termal dayanım açısından bariyer malzemesi olarak uygun görülmüştür ve ön deneylerde üretilen malzemelerin iyodür, perteknetat ve selenit anyonları için yeterli seçiciliği gösterdiği belirlenmiştir [46].

$\mathrm{Su}$ ve diğerleri (2011) Oktadesil trimetil amonyum, oktadesil benzil dimetil amonyuml, dioktadesil dimetil amonyum kullanarak hazırladıkları organobentonitlerle sulu çözeltilerde $\mathrm{As}(\mathrm{V})$ ve As(III) giderimini incelemiş̧lerdir. Modifiye edilmeyen bentonitin $0,043 \mathrm{As}(\mathrm{V})$ and $0.036 \mathrm{mg} / \mathrm{g}$ As(III) adsorplarken oktadesil benzil dimetil amonyum kullanarak üretilen organobentonitin $0,288 \mathrm{mg} / \mathrm{g} \mathrm{As}(\mathrm{V})$ ve $0,102 \mathrm{mg} / \mathrm{g}$ As(III) adsorpladığ 1 tespit edilmiştir. As(V) ve As(III) adsorpsiyonunun çözelti pH'ına çok bağl1 olduğu, diğer iyonların varlığının As(III) adsorpsiyonunu etkilemediği ancak $\operatorname{As}(\mathrm{V})$ adsorpsiyonunu oldukça azalttığ1 gözlenmiştir.Üretilen organobentonitin tekrar kullanılabilirliğinin araştırldığı deneylerde $\mathrm{NaOH}$ çözeltisi kullanıldığında $\% 30.32 \quad \mathrm{As}(\mathrm{V})$ ve $\% \quad 14,72 \quad \mathrm{As}(\mathrm{III})$ anyonunun, $\mathrm{HCl}$ çözeltisi kullanıldığında ise \% 74,61 $\mathrm{As}(\mathrm{V})$ ve \% 29,44 As(III), anyonunun çözeltiye geçtiği belirlenmiştir [32].

Chitrakar ve diğerleri (2012) hekzadesil piridinyum ile modifiye edilmiş Na-montmorillonit mineralinde perkloratın anyon değiştirme özelliklerini incelemişlerdir. $0,01 \mathrm{mg} / \mathrm{dm}^{3}$ ve $0,10 \mathrm{mg} / \mathrm{dm}^{3}$ derişimli iki çözelti ile yapılan deneylerde, modifiye montmorillonitle perklorat iyonunun hızlı bir şekilde çözeltiden uzaklşatırıldığı ve 4 saatte dengeye geldiği gözlenmiştir. Çalışmada perklorat konsantrasyonunun, çözelti $\mathrm{pH}$ değerinin ve diğer iyonların varlığının etkiside incelenmiştir. Perklorat adsorpsiyonunun Langmuir izotermi modeline uyduğu, hem asidik hem de bazik çözeltilerde perklorat iyonlarının etkili bir şekilde uzaklaştırıldığı，0,10, 1,0 ve $2.0 \mathrm{mmol} / \mathrm{dm}^{3}$ derişimli çoklu anyon çözeltilerinde modifiye bentonitin anyon seçiciliği $\mathrm{HPO}_{4}{ }^{2}<\mathrm{SO}_{4}{ }^{2}<\mathrm{NO}_{3}<\mathrm{ClO}_{4}$ şeklinde gerçekleştiği tespit edilmiştir. $\mathrm{Bu}$ seçiciliğin iyonların artan hidrasyon enerjileriyle ilgili olduğu belirtilmiş̧ir. [33]
Milutinovi -Nikoli ve diğerleri (2014) sulu çözeltilerde ${ }^{99} \mathrm{TcO}_{4}$ anyonu olarak bulunan Teknesyum-99 radyoizotopunun farklı koşullarda üretilen organobentonitlere adsorpsiyonunu incelemişlerdir. HDTMA/ bentonit oranının üretilen malzemelerin adsorpsiyon kabliyetine etkisinin araştırıldığı çalışmada, bentonitin KDK değerinin üzerinde HDTMA kullanılarak üreilen malzemelerde ${ }^{99} \mathrm{Tc}$ anyonlarını etkin bir şekilde adsoprladığ gözlenmiştir. KDK değerinin 2 ve 3 katı ile hazırlanan organo-bentonitler deneysel olarak güvenli bir şekilde çalışlabilecek aktiviteye sahip ${ }^{99} \mathrm{mcO}_{4}^{-}$anyonlarınının tamamını adsorpladığı gözlenmiştir. HDTMA katyonlarının bentonit aratabakası içerisinde yerleşimi adsorpsiyon mekanizmasını etkilemektedir. Adsorpsiyon hızını belirleyen basamakların ve kinetik modelin bilinmesi adsorpsiyon mekanizması hakkında bilgi verebilir [49]. Ayrıca büyük ölçekli adsorpsiyon sisteminin tasarımında maksimum adsorpsiyon kapasitesi ve etkileşim süresinin yanı sıra adsorpsiyonun gerçekleşme hızının belirlenmesi en önemli faktörlerden biridir [78]. Bu nedenle Milutinovi Nikoli ve diğerleri (2014) adsorpsiyon hızını belirleyen basamakları ve kinetik modelini belirlemek amaciyla deneysel verilerini çeşitli yüzey tepkimesi ve difüzyon esaslı kinetik modelleri ile test etmişlerdir [49]. Gözenekli malzemeye adsorpsiyon genellikle dört aşamada gerçekleşir: yığın (bulk) difüzyonu, film difüsyonu, intra-partikül difüzyonu ve çözünmüş maddenin yüzeye adsorpsiyonu [79]. Birçok model çözünmüş maddenin yüzeye adsorpsiyonunu adsorpsiyon hızını sınırlayan basamak olarak kabul ederek bu aşamayı kimyasal veya fiziksel etkileşim olabilen yüzey tepkimesi olarak adlandırmaktadır. Yüzey tepkimesi temelli modeller arasında en yaygin olarak kullanılan modeller sanal birinci derece tepkimemodeli ve sanal ikinci derece tepkime modelidir. Milutinovi -Nikoli ve diğerleri (2014) sanal birinci derece tepkime modeli, sanal ikinci derece tepkime modeli ve Elovich denklemi ile ikinci derece tepkime modelinin deneysel olarak elde ettikleri adsorpsiyon verilerine uygunluğunu araştırmışlardır. ${ }^{99} \mathrm{TcO}_{4}^{-}$anyonlarınının ürettikleri organo-bentonitlere adsorpsiyonunun sanal ikinci derece tepkime modeline uyduğunu ortaya koymuşlardır. Difüsyon modellerini de inceleyen araştırmacılar farklı HDTMA/bentonit oranında üretilen organo-bentonitlerin ${ }^{99} \mathrm{Tc}$ anyonlarını adsorplama davranışı birbirinden ayırt edilebilen üç farklı şekilde gerçekleştiğini belirlemişlerdir. Bu mekanizmalardan ilkinde yerdeğiştirebilen katyonların kısmen HDTMA katyonları ile 
yerdeğiştirmesiyle hazırlandığında çok düşük bir adsorpsiyon (ilk yarım saatte $\% 3$ civarında) gerçekleşmiştir. İkincisinde tüm yerdeğiştirebilen katyonlar HDTMA katyonları ile yerdeğiştirdiğinde adsorpsiyonda bir artış (yaklaşık \%40) olduğu ve adsorpsiyonda etkin mekanizmanın da intrapartikül difüzyon olduğu belirlenmiştir. Üçüncüsünde ise bentonitin KDK değerinin üzerinde $(1,5 ; 2 ; 3)$ eklenen HDTMA katyonlariyla üretilen organo-bentonitlerde ise yükleme miktarına bağlı olarak ${ }^{99} \mathrm{Tc}$ anyonlarının tamamını veya tamamına yakınını adsorpladığı ve etkin mekanizmanın film difüzyonu olduğu açılanmıştır [49].

\subsubsection{Katyonik kirliliklerin giderimi}

Odanel-Craver ve Smith'in (2006) $\mathrm{Pb}, \mathrm{Cd}, \mathrm{Zn}$ ve Hg ağır metallerinin kalsiyum bentonite ve iki farklı organik bileşik ile ürettikleri organo-bentonitlere soğurulmasını inceledikleri çalışmada, organik bileşik türünün, miktarının ve pH'ın soğurulmaya etkisi araştırılmıştır. $\mathrm{Pb}$ ve $\mathrm{Cd}$ soğurulmasındaki pH ile değişimin, $\mathrm{Zn}$ ve Hg soğurulmasına göre daha fazla olduğu gözlenmiştir. Organo-bentonitlerin etkin bir şekilde ağır metalleri sulu çözeltiden uzaklaştırdığı, artan organik madde miktarı ile $\mathrm{Pb}, \mathrm{Cd}$ ve $\mathrm{Zn}$ metallerinin soğurulmasının azaldığ gözlemlenmiştir. Bu azalmanın nedeni de, metallerin büyük kuvaterner amonyum katyonları ile etkili bir şekilde yer değiştirememesi olarak açılanmıştır. $\mathrm{Hg}$ için ise, pH'a göre değişen türlerin sözkonusu diğer elementlerden farklı yapıda olması nedeniyle, iyon değiştirme yerine iyon paylaşımı mekanizması ile soğurulmanın geç̧ekleştiği ve bu nedenle soğurulmanın artan organik madde miktarı ile artmış olabileceği belirtilmiştir [36].

Long ve diğerleri (2013) etil amin ile modifiye edilmiş montmorillonitin (Etil-Mt) ve kalsiyum ile doyurulmuş montmorillonitin (Ca-Mt) sezyum adsorpsiyonunu inceleyerek başlangıç çözeltisi pH değeri, etkileşim süresi, başlangıç Cs+ konsantrasyonu, sıcaklık ve iyonik şiddetin adsorpsiyon üzerindeki etkisini araştırmışlardır. Modifiye ürünlerin karkaterizasyonunu FTIR, BET, SEM, EDS ve Zeta potensiyeli analizleri ile gerçekleştirmişlerdir. Deneysel sonuçlar $\mathrm{Cs}^{+}$adsorpsiyonunun $\mathrm{pH}^{\prime} \mathrm{a}$ bağlı olduğunu göstermiştir. Adsorpsiyon Langmiur izotermi ile tanımlanmış ve maksimum adsorpsiyon kapasitesi Ca-Mt ve Etil-Mt için sırasıyla $60,03 \mathrm{mg} / \mathrm{g}$ ve $80,27 \mathrm{mg} / \mathrm{g}$ olarak tespit edilmiştir. Termodinamik çalışmalar $\mathrm{Cs}+$ adsorpsiyonunun kendiliğinden ve egzotermik olarak gerçekleştiğini göstermiştir. $\mathrm{Na}+, \mathrm{K}+, \mathrm{Ca} 2+$ gibi iyonlarının ortamda bulunması durumunda $\mathrm{Cs}+$ adsorpsiyonunun kisitlandığ 1 gözlenmiştir. Çalışmada Cs + katyonunun adsorpsiyon mekanizması incelendiğinde adsorpsiyonun $\mathrm{Ca}-\mathrm{Mt}$ 'te iyon değişimi ve hidroksil gruplarının yüzey kompleksi oluşumu ile Etil-MT de ise kil yapısında bulunan-NH2 koordinasyonu ve hidroksil gruplarının yüzey kompleksi oluşumu ile gerçekleşebileceği belirtilmiştir. Ayrıca Etil-MT'in yüksek adsorpsiyon kapasitesi ile Cs+ uzaklaştırılmasında kullanılmasının yararlı olacağı belirtilmiştir [80].

\subsubsection{Organik kirliliklerin giderimi}

Wang ve diğerleri (2004) tarafindan yürütülen çalışmada kullanılan yüzey aktif bileşiğe bağlı olarak gerçekleșen iyon değişiminin, montmorillonitin gözenek yapısına, yüzey özelliklerine ve adsorpsiyon özelliğine etkisini incelemek için, kalsiyum bentonit tetrametil amonyum klorür ve HDTMA-Br gibi kuvaterner aminlerle modifiye edilerek, boyar madde adsorpsiyonu incelenmiştir. İyon değişim işleminin bentonit içindeki yerdeğiştiren iyonun büyüklüğüne, moleküler yerleşimine ve hidrasyon derecesine bağlı olarak montmorillonitin yüzey alanını ve gözenek yapısını değiştirdiği belirtilmiştir. Ayrıca yüzey özelliklerindeki bu değişimin boyar madde adsorpsiyonunu arttırdığı belirlenmiştir [72].

Yapar ve diğerleri (2005) tarafindan fenolün adsorpsiyonuna adsorban derişiminin etkisi, adsorban olarak HDTMAbentonit kullanılarak incelenmiştir. Eklenen HDTMA ${ }^{+}$ katyonu miktarının bentonitin KDK değerinin \% 100'ünden büyük olduğu durumlarda bu katyonunun tamamen adsorplandığını tespit etmişlerdir; bunun nedenini de zincir etkileşiminin HDTMA $^{+}$katyonunu adsorplanan tabakada tutacak kadar güçlü olmasıyla açıklamışlardır. Daha sonra \% 100 KDK miktarına eşdeğer miktarda YAM ile üretilen organo-bentonitle, farkl1 katı-sıvı oranları kullanılarak yapılan adsorpsiyon deneylerinde fenol adsorpsiyonu miktarının \% 5 lerden \% 30 değerlerine çıktığı gözlenmiştir; sonuç olarak adsorblayan madde miktarı arttıkça adsorpsiyonda göreceli hızlı bir artış olduğu tespit edilmiştir [63].

Liu ve diğerleri (2008) katyonik YAM'lerdeki alkil zincir yapısının ve derişiminin organo-bentonit üretimine ve fenol adsorpsiyonuna etkisini anlamak için tekli, çiftli ve üçlü alkil zincirleri olan heksadesil trimetil amonyum bromür (HDTMA-Br), dimetil dioktadesil amonyum bromür (DDOA-Br), metil trioktadesil amonyum bromür (MTOA$\mathrm{Br})$ gibi katyonik YAM'leri kullanarak çeşitli organobentonitler üretmişlerdir. Çalışmada artan YAM derişimi ile fenol adsorpsiyonunun arttığı gözlenmiştir; ayrıca alkil 
zincirlerinin yapısı dikkate alındığında, üçlü alkil zincirli YAM (MTOA-Br) kullanılarak üretilen organo-bentonit ile fenol adsorpsiyonu, en yüksek değeri almıştır[41].

Mirmohamadsadeghi ve diğerleri (2012) bentoniti doğal hali ile ve hidroklorik asit ile muamele ettirerek saflaştırdıktan sonra \% 100 KDK'ne eşdeğer miktarda hekzadesil trimetil amonyum bromür ile modifiye ederek doğal, asitle aktiflenmiş ve bunlardan üretilmiş organobentonitlerde fenol adsorpsiyonunu araştırmışlardır. Asit ile muamele edilen bentonitten $\mathrm{Na}, \mathrm{Ca}$, K ve Mn'ın uzaklaştı̆̆ 1 ve yüzey alanının \% 30 arttığı, üretilen modifiye bentonitlerde de asitle muamele edilen bentonitle üretilen organobentonitin yüzey alanının \% 40 daha fazla olduğu tespit edilmiştir. Çalışmada üretim öncesi asitle muamele edilmesinin simektitin yüzey özelliklerini geliştirdiği belirtilmiştir. Modifikasyonun fenol adsorpsiyonuna etkisini görmek için çeşitli kinetik ve denge deneyleri gerçekleştirilmiştir. Adsorpsiyon kapasitesinin doğal bentonitten 10 kat daha fazla olduğu fenol adsorpsiyonunun hızlı gerçekleştirği ve 30 dakika içinde dengeye ulaştığı belirtilmiştir. Adsorpsiyonun fiziksel, egzotermik olduğu ve Henry ve Freundlich izotermleri ile tanımlandığı belirtilmiştir [42].

Fatimah ve Huda (2013) setil trimetil amonyum (CTMA) ekleyerek ürettikleri organo-bentonitlerde toluen adsorpsiyonunu ve CTMA miktarının, kilin KDK değerinin ve CTMA/KDK oranının üretilen organo-bentonitin fizikokimyasal özelliklerine ve toluen adsorplama kabiliyetine etkisini araştırmışlardır. Yapılan çalışmada CTMA/KDK oranının ürünün fizikokimyasal özellikleri ve adsorpsiyon kapasitesi üzerinde önemli bir etkisi olduğu tespit edilmiştir [43].

Chen ve diğerleri (2014) setil trimetil amonyum (CTMA) ile ürettikleri organo-bentonitlerin kansorejen bir madde olan nitrosamin kirliliklerinin sulu çözeltilerden uzaklaştırılmasında kullanılabilirliğini araştırmışlardır. Nitrosodifenilaminin (NDPhA) soğrulma veriminin NDPhA başlangıç derişimine bağlı olarak değişmediği ancak artan organo-bentonit miktarına bağlı olarak verimin arttığı gözlenmiş̧ir. Difenilaminin (DPhA) başlangıç derişiminin ve organo-bentonit miktarının ise DPhA soğrulma verimi üzerinde önemli bir etkisi olduğu tespit edilmiştir [44].

\subsection{4 Çeşitli kirliliklerin giderimi}

Riebe ve diğerleri (2001) tarafindan farklı miktarlarda $\mathrm{HDPy}^{+}$katyonu eklenerek üretilmiş organo-bentonitlerdeki radyoaktif $\mathrm{I}^{-}, \mathrm{TcO}_{4}^{-}, \mathrm{Cs}^{+}$ve $\mathrm{Sr}^{2+}$ iyonlarının adsorpsiyonu incelenmiştir. Deney sonuçları elektrolit çözeltisinin iyonik şiddeti arttıkça, tutunmanın azaldığını ve eklenen $\mathrm{HDPy}^{+}$ katyonu miktarı arttıkça anyonik radyonüklidlerin tutunumu artarken, katyonik radyonüklidlerin tutunumunun azaldığını göstermiş̧tir. Anyonların tutunması, $\mathrm{HDPy}^{+}$katyonunun bentonit bünyesine KDK'nin \% 100 miktarından fazla alınması ve/veya $\mathrm{HDPy}-\mathrm{Cl}$ moleküllerinin bentonit bünyesine alınması sonucu, tanecik yüzey yükünün negatiften pozitife dönüşümü ile açıklanmıştır. Üretilen malzemelerde gözlenen yüksek termal dayanımın, organobentonitlerin jeoteknik bariyer olarak nükleer atıkların depolanmasında önemli olduğu belirtilmiştir [81].

Lee ve diğerleri (2002) uygun miktarda katyonik YAM ile kaplanan bentonit yüzeyinin, hem organik hem de inorganik kirliliklerin adsorpsiyonunda kullanılabilirliğini araştırmak için, sodyum bentonite farklı KDK oranlarında HDTMA ${ }^{+}$ ekleyerek, ürettikleri organo-bentonitte $\mathrm{Pb}$ ve klorbenzenin adsorpsiyonunu araştırmışlardır; artan $\mathrm{HDTMA}^{+}$miktarı ile klorbenzen adsorpsiyonu artarken, $\mathrm{Pb}$ adsorpsiyonunun azaldığ1 gözlenmiştir. $\mathrm{Bu}$ durumun organik madde ve ağır metalin adsorpsiyon mekanizmasındaki farklılıktan kaynaklandığ 1 belirtilmiştir. Klorbenzen aratabakada bulunan organik maddeye tutunurken, organo-bentonitlerde $\mathrm{HDTMA}^{+}$katyonunun girmediği katyon değişim bölgelerine, $\mathrm{Pb}$ tutunmakta ve bentonitin kenarlarına bağlanmaktadır. Çalışmada üretilen organo-bentonitlerin, atıkların depolandığ alandaki sızıntı sularındaki $\mathrm{Pb}$ derişimine göre, etkin olabileceği belirtilmektedir [82].

Yan ve diğerleri (2007) sodyum ve kalsiyum montmorillonite $\left(\mathrm{Na}^{+}\right.$- ve $\mathrm{Ca}^{2+}$-montmorillonit) ve $\mathrm{HDTMA}^{+}$ katyonu ile modifiye edilmiş $\mathrm{Na}^{+}$- ve $\mathrm{Ca}^{2+}$-montmorillonite, fenol ve kurşunun birlikte ve ayrı ayrı adsorpsiyonunu araştırmışlardır. Şekil 3'deki soğurulma izotermlerinde görüldüğü gibi, $\mathrm{q}_{\mathrm{e}}$ adsorplanan fenol miktarı (mmol kg$\left.{ }^{1}\right)$ ve $\mathrm{C}_{\mathrm{e}}$ denge çözeltisindeki fenol derişimi $\left(\mathrm{mmol} \mathrm{L}^{-1}\right)$ olmak üzere, fenol adsorpsiyonu ham bentonit ve üretilen malzemelerde HDTMA-Na+ ${ }_{-}^{+}$HDTMA-Ca ${ }^{2+}->\mathrm{Na}^{+}-$ $>\mathrm{Ca}^{2+}$-montmorillonit sırasıyla gerçekleşmiş̧tir. Ancak, ortamda $\mathrm{Pb}$ olduğunda $\mathrm{Na}^{+}$- ve $\mathrm{Ca}^{2+}$-montmorillonitte fenolün adsorpsiyonu önemli oranda azalırken, kurşunun adsorpsiyonunun fenol varlığından pek etkilenmediği gözlenmiştir. Ayrıca, fenolün $\mathrm{HDTMA}^{+}$eklenerek üretilmiş $\mathrm{Na}^{+}$- ve $\mathrm{Ca}^{2+}$-montmorillonitte adsorpsiyonuna, ortamdaki kurşun varlığının etkisi çok az olmuştur ve adsorpsiyon miktarı önemli oranda artmıştır [10]. 
a)

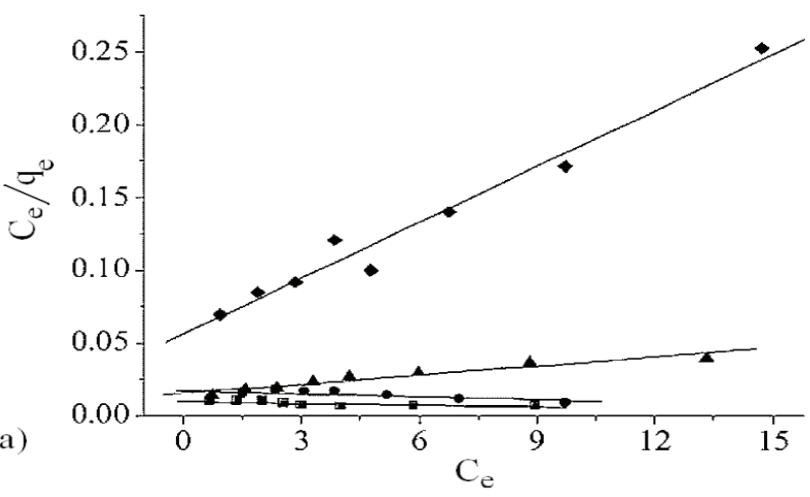

b)

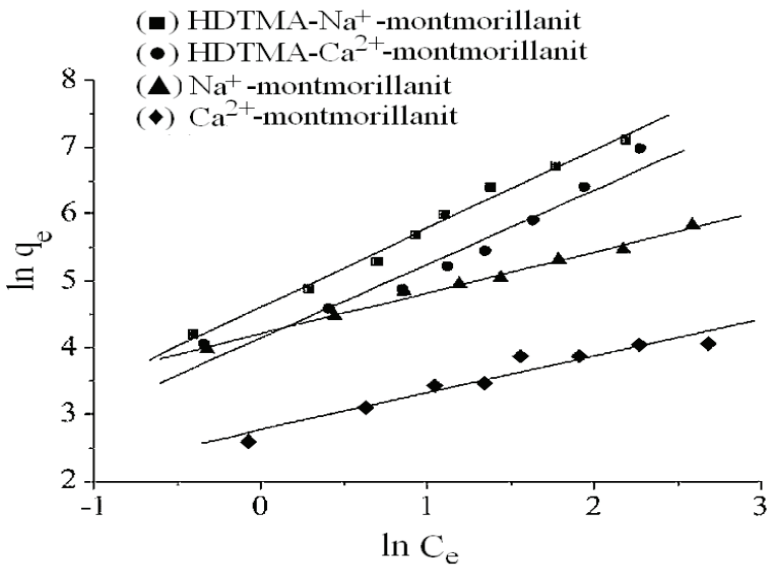

Şekil 3. Fenol soğurulması için Langmuir (a) ve Freundlich (b) denklemleri uyum eğrileri ([10]Yan ve diğerleri, 2007'den uyarlanmıştır)

Shakir ve diğerleri (2011) çalışmalarında setiltrimetl amonyum katyonları ile modifiye edilen bentonitleri kullanarak 137Cs(I), 60Co(II) and 152+154Eu(III) katyonik radyonüklitlerinin ve kimyasal olarak zehirli olan kromotrop2B anyonunun radyoaktif atık sularından uzaklaştırılmasını araştırmışlardır [47]. Modifikasyon elementel analiz, XRD ve FT-IR spektroskopisi yöntemleriyle tespit edilmiştir. Çalışmada bentonit modifikasyonunun organik ve inorganik anyonların ve iyonik olmayan organik maddelerin soğrulmasını önemli ölçüde artırdığı ancak katyonik türlerin sorpsiyonunu oldukça azalttığına değinilmiştir. Ancak bu sorunun kısmi modifikasyonla aşılabileceği vurgulanmıştır. $\mathrm{Bu}$ kapsamda öncelikle üretilen organobentonitlerdeki YAM miktarının kromotrop-2B anyonunu ve katyonik radyonüklidleri uzaklaştırma verimi üzerindeki etkisi araştırılmıştır. Bentonit \% 78 KDK oranında YAM ile modifiye edildiğinde hem kromotrop-2B anyonunu hem de katyonik radyonüklidleri sulu çözeltiten yeterli düzeyde uzaklaştırğı tespit edilmiştir. Ayrıca çalışmada denge izotermleri incelenmiş kinetik ve termodiamik parametreler belirlenmiştir. Çalışma sonuçları kromotrop-2B anyonunun fiziksel sorpsiyonla, radyonüklidlerin de iyon değişimi ile organobentonite soğrulduğu tespit edilmiştir. Çalışmada, deney koşullarına bağlı olarak organobentonitlerin kromotrop-2B anyonunu \% 100 oranında ve radyonüklidleri de $>\% 99$ oranında uzaklaştırabildiği gösterilmiştir [47].

Fan ve diğerleri (2014) dodesil sülfobetain kullanarak modifiye ettikleri montmorillonit ninderalinde $\mathrm{Cu}^{2+}$ ve metilen mavisinin (MM) ayrı ayrı ve beraber adsorpsiyonunu incelemişlerdir. $25^{\circ} \mathrm{C}$ sicaklıkta ve pH 5 de $\mathrm{Cu}^{2+}$ ve $\mathrm{MM}$ adsorpsiton kapasitesi sirasiyla montmorillonit mineraline 9,5 ve $150,2 \mathrm{mg} / \mathrm{g}$ olurken üretilen organo-bentonitte bu değerler 10,2 ve 254,0 mg/g'a ulaşmıştır. Modifikasyonun montmorillonitin adsorpsiyon kapasitesini artırdığından üretilen malzemenin MM uzaklaştırılmasında daha yararlı olduğu belirtilmiştir. Dubinin-Radushkevitch (D-R) denklemi $\mathrm{Cu}^{2+}$ ve MM'nin modifiye ürüne kimyasal iyon değiştirme tepkimesi ile adsorplandığını göstermiştir. Yapılan adsorpsiyon termodinamiği araştırmalarıda tepkimelerin kendiliğinden gelişen endotermik bir süreç olduğunu ortaya koymuştur. $\mathrm{Cu}^{2+}$ ve MM'nin bir arada kullanıldığı adsorpsiyon deneylerinde ise rekabetçi bir adsopsiyonun gerçekleştiği ve modifiye ürünün MM'ye karşı daha fazla ilgi ve seçicilik gösterdiği gözlenmiştir [50]. Li ve diğgerleri (2014) yaptıkları çalışmada düşük maliyetli 13 soğurucu malzemede Teknesyum-99 ( $\left.{ }^{99} \mathrm{Tc}\right)$, iyot$129\left({ }^{129} \mathrm{I}\right)$, and sezyum-137 $\left({ }^{137} \mathrm{Cs}\right)$ radyoizotoplarının adsorpsiyonunu araştırmışlardır. Yapılan çalışmada kullanılan iki organokilin $\mathrm{TcO}_{4}^{-}\left(\mathrm{Kd}>1 \times 10^{5} \mathrm{~mL} / \mathrm{g}\right), \mathrm{I}^{-}(\mathrm{Kd}$ $\left.>1 \times 10^{4} \mathrm{~mL} / \mathrm{g}\right)$, ve $\mathrm{Cs}^{+}\left(\mathrm{Kd}>1 \times 10^{3} \mathrm{~mL} / \mathrm{g}\right)$ radyonüklidlerini büyük miktarda ve büyük kısmını geri dönüşümsüz şekilde adsorpladığı görülmüştür. Aktif karbonun $\mathrm{TcO}_{4}^{-}\left(\mathrm{Kd}>1 \times 10^{5}\right.$ $\mathrm{mL} / \mathrm{g})$ ve $\mathrm{I}^{-}\left(\mathrm{Kd}=6,9 \times 10^{3} \mathrm{~mL} / \mathrm{g}\right)$ radyonüklidlerini ve YAM ile modifiye edilen şabazitin $\mathrm{TcO}_{4}^{-}\left(\mathrm{Kd}>2,5 \times 10^{4} \mathrm{~mL} / \mathrm{g}\right)$ ve $\mathrm{Cs}^{+}\left(\mathrm{Kd}>6,5 \times 10^{3} \mathrm{~mL} / \mathrm{g}\right)$ etkili bir şekilde adsorpladığ 1 görülürken kullanılan diğer soğurucu malzemelerin ise genelde sadece bir radyonüklidin uzaklaştırılmasında etkili olduğu gözlemlenmistir [48].

Makale içinde verilen çalışmalar dışında, organobentonitlerin çeşitli kirliliklerin gideriminde kullanılmasına yönelik yapılan diğer bazı çalışmalar da son 5 yıl için Tablo 1'de özetlenmiştir. Bu çalışmalarda, anyonik, katyonik ve organik kirliliklerin ayrı ayrı veya bir arada bulunduğu durumlarda modifiye ürünlerin etkin olabildiğini göstermiştir.

Ancak bu kirliliklerin gideriminde üretim koşullarının önemli rol oynadığı gözlenmiştir. Özellikle anyonik kirliliklerin gideriminde kullanılan YAM miktarının önemli olduğu ve ancak bentonitin $\mathrm{KDK}$ değerinin üzerinde 
YAM kullanılması durumunda üretilen malzemenin etkin olduğu yapılan çalışmalarda ortaya konmuştur. Bu durum bentonitlerin KDK değerinin üzerinde YAM kullanıldığında yüzey yükünün negatiften pozitife dönüşmesinden ve adsorban ile kirlilik arasında elektrostatik etkileşimin meydana gelmesinden kaynaklanmaktadır. Bu özellikleri ile kimyasal özellikleri farklı kirliliklerin bir arada bulunduğu atık sularda, kirliliklerin özellikleri göz önüne alınarak kolay bir şekilde üretilen organo-bentonitler kullanılabilir. Çevresel kirliliklerin önlenmesinde oldukça umut verici sonuçların alındığı organo-bentonitlerin kullanımının giderek yaygınlaşacağı düşünülmektedir.

Tablo 1. Organobentonitlerin çeşitli kirliliklerin gideriminde kullanılmasına yönelik yapılan bazı çalışmalar

\begin{tabular}{|c|c|c|c|c|c|}
\hline Malzeme & Organik Bileşik & Amaç & Adsorbe Edilen Malzeme & Yil & Kaynak \\
\hline Montmorillonit & Tetrametil amonyum & $\begin{array}{l}\text { Üretim, karakterizasyon ve } \\
\text { adsorpsiyon }\end{array}$ & Toluen & 2009 & {$[83]$} \\
\hline $\begin{array}{l}\text { Montmorillonit } \\
\text { Kaolin }\end{array}$ & Tetrametil amonyum & $\begin{array}{l}\text { Üretim, karakterizasyon ve } \\
\text { adsorpsiyon, adsorpsiyon } \\
\text { kinetiği, izotermleri ve } \\
\text { termodinamik parametrelerinin } \\
\text { belirlenmesi }\end{array}$ & $\mathrm{Fe}(\mathrm{III}), \mathrm{Co}(\mathrm{II}), \mathrm{Ni}(\mathrm{II})$ & 2009 & {$[84]$} \\
\hline Bentonite & 1,6-diamino hekzan & $\begin{array}{l}\text { Üretim, karakterizasyon ve } \\
\text { adsorpsiyon, Adsorpsiyon } \\
\text { kinetiği, izotermleri ve } \\
\text { termodinamik parametrelerinin } \\
\text { belirlenmesi, deney } \\
\text { koşullarının adsorpsiyona } \\
\text { etkisi }\end{array}$ & $\begin{array}{l}\text { Reaktif Mavi } 19 \text { tekstil } \\
\text { boyas1 }\end{array}$ & 2010 & {$[11]$} \\
\hline $\begin{array}{l}\text { Bentonit, Hallosit, } \\
\text { Kaolin }\end{array}$ & Hekzadesil trimetil amonyum $\mathrm{Br}$ & $\begin{array}{l}\text { Üretim, karakterizasyon ve } \\
\text { adsorpsiyon }\end{array}$ & Nitrat & 2010 & {$[85]$} \\
\hline Bentonit & Oktadesil trimetil amonyum $\mathrm{Br}$ & $\begin{array}{l}\text { Üretim, karakterizasyon } \\
\text { ve adsorpsiyon, deney } \\
\text { koşullarının adsorpsiyona } \\
\text { etkisi }\end{array}$ & $\mathrm{U}(\mathrm{VI})$ & 2010 & {$[86]$} \\
\hline Bentonit & $\begin{array}{l}\text { Setil trimetil amonyum } \mathrm{Br} \text {, } \\
\text { poliakrilamid }\end{array}$ & $\begin{array}{l}\text { Üretim, karakterizasyon ve } \\
\text { adsorpsiyon }\end{array}$ & Fenol, nitrobenzen, anilin & 2010 & {$[87]$} \\
\hline Bentonit & $\begin{array}{l}\text { Hekzadesil trimetil amonyum } \mathrm{Br} \text {, } \\
\text { poli(etilen glikol) bütil eter }\end{array}$ & $\begin{array}{l}\text { Üretim, karakterizasyon, } \\
\text { adsorpsiyon }\end{array}$ & o-, m- ve p-nitrofenoller & 2011 & {$[12]$} \\
\hline Montmorillonit & $\begin{array}{l}\text { Setil piridinyum } \mathrm{Cl} \text {, benzetonyum } \\
\mathrm{Cl} \text {, Hekzadesil trimetil amonyum } \\
\mathrm{Cl}\end{array}$ & $\begin{array}{l}\text { Üretim, karakterizasyon, } \\
\text { adsorpsiyon, deney } \\
\text { koşullarinın adsorpsiyona } \\
\text { etkisi }\end{array}$ & Bromat & 2011 & {$[88]$} \\
\hline Bentonit & $\begin{array}{l}\text { Çitosan, hekzadesil trimetil } \\
\text { amonyum } \mathrm{Br} \text {, }\end{array}$ & $\begin{array}{l}\text { Üretim, karakterizasyon, } \\
\text { adsorpsiyon, desorpsiyon, } \\
\text { yeniden kullanım, farklı deney } \\
\text { koşullarının adsorpsiyona } \\
\text { etkisi }\end{array}$ & Boya (Zayıf Asit Skarlet) & 2012 & [89] \\
\hline Montmorillonit & $\begin{array}{l}\text { Tetrametil amonyum } \mathrm{Br} \text {, } \\
\text { dodesiltrimetil amonyum } \mathrm{Br} \text {, } \\
\text { hekzadesil trimetil amonyum } \mathrm{Br}\end{array}$ & $\begin{array}{l}\text { Üretim, karakterizasyon, } \\
\text { antibiyotik atıklarının } \\
\text { adsorpsiyonu }\end{array}$ & Tetrasiklin & 2012 & {$[90]$} \\
\hline Montmorillonit & $\begin{array}{l}\text { Hekzadesil trimetil } \\
\text { amonyum oktadesilamin, } \\
\text { dihidroksietilmetilamonyum }\end{array}$ & $\begin{array}{l}\text { Üretim, karakterizasyon, } \\
\text { adsorpsiyon, kinetik, } \\
\text { denge ve termodinamik } \\
\text { parametrelerin belirlenmesi, } \\
\text { deney koşullarının etkisinin } \\
\text { belirlenmesi }\end{array}$ & Amoksilin & 2013 & {$[91]$} \\
\hline Bentonit & Setil trimetil amonyum $\mathrm{Br}$ & $\begin{array}{l}\text { Üretim, karekterizasyon, } \\
\text { adsorpsiyon }\end{array}$ & 2-mercaptobenzothiazole & 2013 & {$[92]$} \\
\hline Montmorillonit & Gemini yüzey aktif madde & $\begin{array}{l}\text { Üretim, karakterizasyon, } \\
\text { adsorpsiyon, desorpsiyon, } \\
\text { kinetik ve termodinamik } \\
\text { parametrelerin belirlenmesi }\end{array}$ & 2-naftol, fenol & 2015 & {$[93]$} \\
\hline Montmorillonit & $\begin{array}{l}\text { Tetrafenilfosfonyum, } \\
\text { amiltrifenilfosfonyum }\end{array}$ & $\begin{array}{l}\text { Üretim, karakterizasyon, } \\
\text { adsorpsiyon }\end{array}$ & Aromatik bileşikler & 2015 & {$[94]$} \\
\hline
\end{tabular}




\section{SONUÇLAR}

Günlük hayatı etkileyen birçok alanda organo-bentonitlerin kullanımı her geçen gün yaygınlaşmaktadır; organobentonitlerle ilgili konulardaki araştırmaların ilerlemesiyle organo-bentonitlerin kullanım alanlarının daha da genişleyeceği ve dünyada ve Türkiye'de mevcut zengin bentonit rezervlerinin, istenen özelliklerde organo-bentonit üretimine kaynak sağlayacağı görülmektedir. Bu çalışmada, organo-bentonitler konusunda incelenen araştırmalar göstermektedir ki:

- Bentonit modifikasyonunda çoğunlukla kullanılan bileşikler kuvaterner amonyum tuzlarıdır.

- Çoğunlukla iyon değiştirme yöntemiyle organo-bentonit üretimi yapılmaktadır.

- Üretilen organo-bentonit malzemelerin yapısı, modern analiz yöntemleri ile incelenebilmektedir.

- Farklı koşullarda üretilen organo-bentonitler farklı katyonik, anyonik ve organik kirliliklerin giderilmesinde yüksek verimle kullanılabilmektedir.

\section{TEŞEKKÜR}

Bu çalışma 33041 numaralı İ.T.Ü. Lisansüstü Tezlerini Destekleme Projesi kapsamında hazırlanmıştır.

\section{KAYNAKLAR}

[1] Cheremisinoff, N.P. (2002). Handbook of Water and Wastewater Treatment Technologies, Elsevier Inc., $1-61$.

[2] Donat, R., Akdogan, A., Erdem, E. ve Cetisli, H. (2005). Thermodynamics of $\mathrm{Pb}^{2+}$ and $\mathrm{Ni}^{2+}$ adsorption onto natural bentonite from aqueous solutions. J Colloid Interf Sci, 286, 1, 43-52.

[3] Busca, G., Berardinelli, S., Resini, C. ve Arrighi, L. (2008). Technologies for the removal of phenol from fluid streams: a short review of recent developments. J Hazard Mater, 160, 265-288.

[4] Masuda, H., Higashitani, K. ve Yoshida, H. (2006). Powder Technology Handbook, Third Edition CRC Taylor \& Francis, 878.

[5] Lu, S., Pugh, R.J. ve Forssberg, K.S.E. (2005). Interfacial Separation of Particles. In: Studies. In: Interface Science, Möbius, D., Miller, R. (eds.), 20, Series, Elsevier, 97-171.

[6] Bradbury, M.H. ve Baeyens, B. (1997). A mechanistic description of $\mathrm{Ni}$ and $\mathrm{Zn}$ sorption on Na-montmorillonite
Part II: modelling. J Contam Hydrol, 27, 223-248.

[7] Bradbury M.H. ve Baeyens, B. (2002). Sorption of

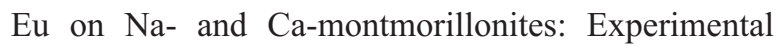
investigations and modelling with cation exchange and surface complexation. Geochim Cosmochim Ac, 66, $13,2325-2334$.

[8] Çinku K., Boylu, F., Duman, F. ve Çelik, M.S. (2010). Bentonitlerin zenginleştirme ve soda ile aktivasyonunda sudaki iyon varlığı ve miktarını ürün özellikleri üzerindeki etkisi. İ.Ü. Mühendislik Bilimleri Dergisi, 1, 918.

[9] Yıldız, N., Gönülşen, R. ve Çalımlı, A. (2006). Tek ve çift katyonlu organo-bentonitlerin hazırlanması ve karakterizasyonu. KIBİTED, 1, 2, 93-105.

[10] Yan L., Shan X., Wen B. ve Zhang S. (2007). Effect of lead on the sorption of phenol onto montmorillonites and organo-montmorillonites. J Colloid Interf Sci, 308, $11-19$.

[11] Gök, O., Özcan, A.S. ve Özcan A. (2010). Adsorption behavior of a textile dye of Reactive Blue 19 from aqueous solutions onto modified bentonite. Appl Surf Sci, 256, 5439-5443.

[12] Koyuncu, H., Yıldız, N., Salgın, U., Koroğlu, F. ve Çalıml, A. (2011). Adsorption of o-, m- and p-nitrophenols onto organically modified bentonites. J Hazard Mater, 185, 1332-1339.

[13] Krishna, B.S., Murty, D.S. R. ve Prakash, B.S.J. (2001). Surfactant-modified clay as adsorbent for chromate. Appl Clay Sci, 20, 65-71.

[14] Slade, P.G. ve Gates, W.P. (2004). The swelling of HDTMA smectites as influenced by their preparation and layer charges. Appl Clay Sci, 25, 93-101.

[15] Karahan, S., Yurdakoç, M., Seki, Y. ve Yurdakoç, K. (2006). Removal of boron from aqueous solution by clays and modified clays. J Colloid Interf Sci, 293, 36-42.

[16] Park, Y., Ayoko, G.A. ve Frost, R.L. (2011). Application of organoclays for the adsorption of recalcitrant organic molecules from aqueous media. J Colloid Interf Sci, 354, 292-305.

[17] Yariv, S. ve Cross H. (2002). Organo-clay complexes and interactions, CRC Press, New York.

[18] Lagaly, G., Ogawa, M. ve Dekany, I. (2006). Clay mineral organic interactions. In: Developments in Clay Science, Handbook of Clay Science, Bergaya, F., Theng, B.K.G., Lagaly G. (eds.), Elsevier, Amsterdam, 1, 309-377. 
[19] Oruçoglu, E. ve Haciyakupoğlu, S. (2010). Organobentonitler ve karakterizasyonlarında kullanılan yöntemler. KİBİTED, 1, 4, 21-37.

[20] Jordan, J.W. (1949). Alteration of the properties of bentonite by reaction with amines. Mineral Mag, 28, 598-605.

[21] Jordan J.W. (1950). Organophilic bentonites II. J Phys Colloid Chem, 54, 1196-1208.

[22] Slabaugh, W.H. ve Culbertson, J.L. (1951). The effect of certain reagents upon the properties of bentonite colloids II organic Amines. J Phys Chem, 55 7, 1131-1139.

[23] Greenland, D.J. ve Quirk, J.P. (1960). Adsorption of 1-n-alkyl-pyridinium bromides by montmorillonite. Clay Clay Miner, 9, 484-499.

[24] Mortimer, J.V. ve Gent, P.L. (1964). The use of organoclays as gas chromatographic stationary phases. Anal Chem, 36, 4, 754-756.

[25] Slabaugh, W.H. (1971). Surface Chemistry of Thermally Decomposed Organo-Montmorillonite Complexes. Clay Clay Miner, 19, 201-204.

[26] Franco, M.A., Gessa, C. ve Cariati F. (1978). Identification of tetramethylammonium ion in methylated $\mathrm{NH}_{4}$-bentonite. Clay Clay Miner, 26, 1, 7375.

[27] Mortland, M.M., Shaobai, S. ve Boyd, S.M. (1986). Clay-organic complexes as adsorbents for phenol and chlorophenols. Clay Clay Miner, 34, 5, 581-585.

[28] Zhang, Z., Sparks, D.L. ve Scrivner N.C. (1993). Sorption and desorption of quaternary amine cations on clays. Environ Sci Technol, 27, 1625-1631.

[29] Choy, J.H., Kwak, S.Y., Han, Y.S. ve Kim, B.W. (1997). New organo-montmorillonite complexes with hydrophobic and hydrophilic functions. Mater Lett, 33, 143-147.

[30] Moraru V.N. (2001). Structure Formation of Alkylammonium Montmorillonites in Organic Media. Appl Clay Sci, 19, 11-26.

[31] Senturk, H.B., Ozdes, D., Gundogdu, A., Duran, C. ve Soylak, M. (2009). Removal of phenol from aqueous solutions by adsorption onto organomodified Tirebolu bentonite: Equilibrium, kinetic and thermodynamic study. J Hazard Mater, 172, 353-362.

[32] Su J., Huang H.G., Jin X.Y., Lu X.Q. ve Chen Z.L. (2011). Synthesis; characterization and kinetic of a surfactant-modified bentonite used to remove As(III) and $\mathrm{As}(\mathrm{V})$ from aqueous solution. J Hazard Mater, 185,
1, 63-70.

[33] Chitrakar, R., Makita, Y., Hirotsu, T. ve Sonoda, A. (2012). Montmorillonite modified with hexadecylpyridinium chloride as highly efficient anion exchanger for perchlorate ion. Chem Eng J, 191, 141146.

[34] Krishna, B.S., Murty, D.S. R. ve Prakash, B.S.J. (2000). Thermodynamics of chromium (VI) anionic species sorption onto surfactant-modified montmorillonite clay. J Colloid Interf Sci, 229, 230-236.

[35] Majdan, M., Maryuk, O., Pikus, S., Olszewska, E., Kwiatkowski, R. ve Skrzypek H., (2005). Equilibrium, FTIR, scanning electron microscopy and small wide angle X-ray scattering studies of chromates adsorption on modified bentonite, J Mol Struct, 740, 203-211.

[36] Odanel-Craver, V.A. ve Smith, J.A. (2006). Quaternary ammonium cation loading and $\mathrm{pH}$ on heavy metal sorption to $\mathrm{Ca}$ bentonite and two organo-bentonites, $\mathrm{J}$ Hazard Mater B, 137, 1102-1114.

[37] Atia, A.A., (2008). Adsorption of chromate and molybdate by cetylpyridinium bentonite, Appl Clay Sci, 41, 73-84.

[38] Lee, S.M. ve Tiwari, D. (2012). Organo and inorganoorgano-modified clays in the remediation of aqueous solutions: An overview. Appl Clay Sci, 59-60, 84-102.

[39] Bartelt-Hunt, S.L., Burns, S.E. ve Smith, J.A. (2003). Nonionic organic solute sorption onto two organobentonites as a function of organic-carbon content. J Colloid Interf Sci, 266, 251-258.

[40] Moronta, A., (2004). Catalytic and adsorption properties of modified clay surfaces. In: Interface Science and Technology, Clay Surfaces: Fundamentals and Applications, Wypych. F. ve Satyanarayana, K.G. (eds.), Elsevier, 1, 321-344.

[41] Liu, R., Frost, R.L., Martens, W.N. ve Yuan, Y. (2008). Synthesis, characterization of mono, di and tri alkyl surfactant intercalated wyoming montmorillonite for the removal of phenol from aqueous systems. J Colloid Interf Sci, 327, 287-294.

[42] Mirmohamadsadeghi, S., Kaghazchi, T., Soleimani, M. ve Asasian, N. (2012). An efficient method for clay modification and its application for phenol removal, from wastewater. Appl Clay Sci, 59-60, 8-12.

[43] Fatimah, I. ve Huda T. (2013). Preparation of cetyltrimethylammonium intercalated Indonesian montmorillonite for adsorption of toluene. Appl Clay Sci, 74, 115-120. 
[44] Chen, C., Zhou, W., Yang, Q., Zhu, L. ve Zhu, L. (2014). Sorption characteristics of nitrosodiphenylamine (NDPhA) and diphenylamine (DPhA) onto organobentonite from aqueous solution. Chem Eng J, 240, 487-493.

[45] Bors, J., Dultz, S. ve Riebe, B. (2000). Organophilic bentonites as adsorbents for radionuclides I. Adsorption of ionic fission products. Appl Clay Sci, 16, 1-13.

[46] Riebe, B., Dultz, S. ve Bunnenberg, C. (2005). Temperature effects on iodine adsorption on organoclay minerals I. influence of pretreatment and adsorption temperature. Appl Clay Sci, 28, 9-16.

[47] Shakir, K., Ghoneimy, H.F., Hennawy, I.T., Elkafrawy, A.F., Beheir, S.G.E. ve Refaat, M. (2011). Simultaneous removal of chromotrope $2 \mathrm{~B}$ and radionuclides from mixed radioactive process wastewater using organo bentonite. Eur J Chem, 2, 1, 8393.

[48] Li, D., Kaplan, D.I., Knox, A.S., Crapse, K.P. ve Diprete D.P. (2014). Aqueous 99Tc, 129I and 137Cs removal from contaminated groundwater and sediments using highly effective low-cost sorbents. J Environ Radioactiv, 136, 56-63.

[49] Milutinovi -Nikoli, A., Maksin, D., Jovi -Jovi i, N., Mirkovi, M. Stankovi, D., Mojovi, Z. ve Bankovi, P. (2014). Removal of 99Tc(VII) by organo-modified bentonite.Appl Clay Sci, 95, 294-302.

[50] Fan, H.,Zhou, L., Jiang, X., Huang, Q. ve Lang, W. (2014). Adsorption of $\mathrm{Cu} 2+$ and methylene blue on dodecyl sulfobetaine surfactant-modified montmorillonite. Appl Clay Sci, 95, 150-158.

[51] He, H., Frost R.L. ve Zhu, J. (2004). Infrared study of $\mathrm{HDTMA}^{+}$intercalated montmorillonite. Spectrochim Acta A, 60, 2853-2859.

[52] Ruiz-Hitzky E. ve Van Meerbeek A., (2006). Clay Mineral- and Organoclay-Polymer Nanocomposite. In: Developments in Clay Science, Handbook of Clay Science, Bergaya, F., Theng B. K.G. ve Lagaly G. (eds.), Elsevier, Amsterdam, 1, 583-621.

[53] Murray, H.H., (2006). Applied Clay MineralogyOccurrences, Processing and Application of Kaolins, Bentonites, Palygorskite-Sepiolite, and Common Clays, Developments in Clay Science, Elsevier, Amsterdam, 2,111-130.

[54] Park, S.J., Seo, D.I. ve Lee, J.R. (2002). Surface modification of montmorillonite on surface acid-base characteristics of clay and thermal stability of epoxy/clay nanocomposites. J Colloid Interf Sci, 251, 160-165.
[55] Baldassari, S., Komarneni, S., Mariani, E. ve Villa, C. (2006). Microwave versus conventional preparation of organoclays from natural and synthetic clays. Appl Clay Sci, 31, 134-141.

[56] Tasdelen M.A., Kreutzer J. ve Yagci Y. (2010). In situ synthesis of polymer/clay nanocomposites by living and controlled/living polymerization. Macromol Chem Physic, 211, No 3, 279-285.

[57] Paiva L.B., Morales A.R. ve Díaz F.R.V. (2008). Organoclays: Properties, preparation and applications, Appl Clay Sci, 42, 8-24.

[58] Tiwari R.R., Khilar K.C. ve Natarajan U. (2008). Synthesis and characterization of novel organo montmorillonites. Appl Clay Sci, 38, 203-208.

[59] Jankovi, L., Madejová, J., Komadel, P., JochecMo ková, D. ve Chodák I. (2011). Characterization of systematically selected organo-montmorillonites for polymer nanocomposites. Appl Clay Sci, 51, 438-444.

[60] Lee, S.Y. ve Kim, S.J. (2002). Delamination behavior of silicate layers by adsorption of cationic surfactants. J Colloid Interf Sci, 248, 231-238.

[61] Dultz, S., Riebe, B. ve Bunnenberg, C. (2005). Temperature effects on iodine adsorption on organoclay minerals II. Structural effects. Appl Clay Sci, 28, $17-30$.

[62] Yu, X., Wei, C., Ke, L., Hu, Y., Xie, X. ve Wu, H. (2010). Development of organovermiculite-based adsorbent for removing anionic dye from aqueous solution. J Hazard Mater, 180, 1, 499-507.

[63] Yapar S., Özbudak V., Dias A. ve Lopes A. (2005). Effect of adsorbent concentration to the adsorption of phenol on hexadecyl trimethyl ammonium-bentonite. J Hazard Mater, 121, 1-3, 135-139.

[64] Erdem A.R. ve Uyanık N. (2009). Mikrodalga ile kürleştirilen epoksi nanokompozitlerin polidimetil siloksan ile modifikasyonu. İTÜ Dergisi/C Fen Bilimleri, 7, 1, 67-76.

[65] Majdan, M., Maryuk, O., Gladysz-Plaska, A., Pikus, S. ve Kwiatkowski, R. (2008). Spektral characteristics of the bentonite loaded with benzyldimethyloctadecylammonium chloride, hexadecyltrimethyl-ammonium bromide and dimethyldiocta-decylammonium bromide. J Mol Struct, 874, 101-107.

[66]Feng, X., Hu, G., Meng, X., Ding, Y., Zhang, S. ve Yang, M. (2009). Influence of ethanol addition on the modification of montmorillonite by hexadecyl trimethylammonium bromide. Appl Clay Sci, 45, 239-243. 
[67] Akçay, M. (2006). Characterization and adsorption properties of tetrabutylammonium montmorillonite (TBAM) Clay: Thermodynamic and kinetic calculations. J Colloid Interf Sci, 296, 16-21.

[68] Kozak, M. ve Domka, L. (2004). Adsorption of the quaternary ammonium salts on montmorillonite. J Phys Chem Solids, 65, 441-445.

[69] Yüzer, H., Sarıoğlan, Ş., Koral, M., Doğan, H., Çelik, M.S. ve Karahan, S. (2007). Reşadiye bentonitinden solvent bazlı bentonit üretim prosesinin geliştirilmesi. XIII. Kil Sempozyumu Bildiriler Kitabı, Isparta, 195202, 12-14 Eylül.

[70] Yapar, S. (2009). Physicochemical Study of microwavesynthesized organoclays, Colloid Surface A, 345, 7581.

[71] Behnsen J. ve Riebe B. (2008). Anion selectivity of organo-bentonites. App Geochem, 23, 2746-2752.

[72] Wang, C., Juang , L., Lee, C., Hsu, T., Lee, J. ve Chao, H., (2004). Effects of exchanged surfactant cations on the pore structure and adsorption characteristics of montmorillonite. J Colloid Interf Sci, 280, 27-35.

[73] Lee, S.Y., Cho, W.J., Kim, K.J., Ahn, J.H. ve Lee, M. (2005). Interaction between cationic surfactants and montmorillonites under nonequilibrium condition. J Colloid Interf Sci，284, 667-673.

[74] Bors, J., Patzko, A. ve Dekany, I. (2001). Adsorption behavior of radioiodides in hexadecylpyridiniumhumate complexes. Appl Clay Sci, 19, 27-37.

[75] Özcan, A., Ömeroğlu, Ç., Erdoğan, Y. ve Özcan, A.S. (2007). Modification of bentonite with a cationic surfactant: An adsorption study of textile dye Reactive Blue 19. J Hazard Mater, 140 173-179.

[76] Oral, A., Tasdelen, M.A., Demirel, A.L. ve Yagci, Y. (2009). Poly(cyclohexene oxide)/clay nanocomposites by photoinitiated cationic polymerization via activated monomer mechanism. J Polym Sci A1, 47, 20, 53285335.

[77] Ghiaci, M., Kalbasi, R.J., Khani, H., Abbaspur, A. ve Shariatmadari, H. (2004). Free-energy of adsorption of a cationic surfactant onto Na-bentonite (Iran): Inspection of adsorption layer by X-Ray spectroscopy. J Cheml Thermodyn, 36, 707-713.

[78] Ho, Y.S. (2006). Review of second-order models for adsorption systems. J Hazard Mater, B136, 681-689.

[79] Kuo, C.Y., Wu, C.H. ve Wu, J.Y. (2008). Adsorption of direct dyes from aqueous solutions by carbon nanotubes: Determination of equilibrium, kinetics and thermodynamics parameters. J Colloid Interf Sci, 327, 308-315.

[80] Long, H., Wu, P., Zhu, N. (2013). Evaluation of $\mathrm{Cs}+$ removal from aqueous solution by adsorption on ethylamine-modified montmorillonite, Chem Eng J, 225, 237-244.

[81] Riebe B., Bors, J. ve Dultz, S. (2001). Retardation capacity of organophilic bentonite for anionic fission products. J Contam Hydrol, 47, 255-264.

[82]Lee, J., Choi, J. ve Park, J. (2002). Simultaneous sorption of lead and chlorobenzene by organo-bentonite. Chemosphere, 49, 1309-1315.

[83] Vidal, N.C., Volzone, C. (2009), Analysis of tetramethylammonium-montmorillonite and retention of toluene from aqueous solution, Appl Clay Sci, 45, 4, 227-231.

[84] Bhattacharyya, K.G., Gupta, S.S., (2009). Calcined tetrabutylammonium kaolinite and montmorillonite and adsorption of $\mathrm{Fe}(\mathrm{II}), \mathrm{Co}(\mathrm{II})$ and $\mathrm{Ni}(\mathrm{II})$ from solution, Appl Clay Sci, 46, 2, 216-221.

[85] Xi, Y., Mallavarapu, M., Naidu, R., (2010) Preparation, characterization of surfactants modified clay minerals and nitrate adsorption, Appl Clay Sci, 48, 1-2, 92-96.

[86] Majdan, M.,Pikus, S., Gajowiak, A.,Sternik, D., Zięba, E., Uranium sorption on bentonite modified by octadecyltrimethylammonium bromide, J Hazard Mater, 184, 1-3. 662-670.

[87] Zhu, R., Wang, T., Zhu, J., Ge, F., Yuan, P., He, H. (2010) Structural and sorptive characteristics of the cetyltrimethylammonium and polyacrylamide modified bentonite, Chem Eng J, 160, 1, 220-225.

[88] Chitrakar, R., Makita, Y., Sonoda, A., Hirotsu, T. (2011). Adsorption of trace levels of bromate from aqueous solution by organo-montmorillonite, Appl Clay Sci, 51, 3, 375-379.

[89] Guo , J., Chen, S., Liu, L., Li, B., Yang, P., Zhang, L., Feng, Y., (2012). Adsorption of dye from wastewater using chitosan-CTAB modified bentonites, J Colloid Interf Sci, 382, 1, 61-66.

[90] Liu, N., Wang, M.X., Liu, M.M., F., Liu, Weng, L., Koopal, L.K.,Tan, W.F., (2012). Sorption of tetracycline on organo-montmorillonites, J Hazard Mater, 225-226, 28-35.

[91] Zha, S., Zhou, Y., Jin, X., Chen, Z., (2013). The removal of amoxicillin from wastewater using organobentonite, Journal of Environmental Management, 129, 569-576.

[92] Jing, P., Hou, M., Zhao, P., Tang, X., Wan, H., (2013). 
Adsorption of 2-mercaptobenzothiazole from aqueous solution by organo-bentonite, Journal of Environmental Sciences, 25, 6, 1139-1144.

[93] Yang, S., Gao, M., Luo, Z., Yang, Q. (2015).The characterization of organo-montmorillonite modified with a novel aromatic-containing gemini surfactant and its comparative adsorption for 2-naphthol and phenol,
Chemical Engineering Journal, 268, 125-134.

[94] Kameda , T., Shimamori, S., Yoshioka, T., (2015). Equilibrium studies of the uptake of aromatic compounds from an aqueous solution by montmorillonite modified with tetraphenylphosphonium and amyltriphenylphosphonium, Journal of Alloys and Compounds, 625, 8-12. 